\title{
AVALIAÇÃO DAS BRÂNQUIAS DE Danio rerio EXPOSTOS A DIFERENTES CONCENTRAÇÕES DE GASOLINA E DIESEL
}

\author{
RAFAEL ALVES FREITAS * \\ KADJA DE MORAIS CORREIA * \\ MARIA GIZELDA DE OLIVEIRA TAVARES ** \\ GLÁUCIA M. CAVASIN OLIVEIRA *** \\ ANDRÉIA CINTRA **** \\ HENRIQUE RICIOLE ***** \\ IARA NUNES **** \\ JEFERSON FAGUNDES **** \\ NELSON ROBERTO ANTONIOSI FILHO ******
}

\begin{abstract}
O presente trabalho foi elaborado com o intuito de estudar os efeitos dos combustíveis fósseis nas brânquias do peixe Danio rerio (Cyprinidae). Os animais foram expostos a diferentes concentrações de gasolina e óleo diesel, entre 6,25 \% a $100 \%$, mediante testes ecotoxicológicos. Os resultados demonstraram que os combustíveis em sua composição comum ou pura são letais e em alguns casos provocam severas lesões como, necrose, hipertrofia das células, aneurismas e edemas, levando os animais à morte.
\end{abstract}

PALAVRAS-CHAVE: HISTOPATOLOGIA; BRÂNQUIAS; ECOTOXICOLOGIA; Danio rerio.

* Graduados em Ciências Biológicas pela Faculdade Araguaia (FARA), Estagiários do Laboratório de Histologia, Universidade Federal de Goias (UFG), Goiânia, GO (e-mail: rafaranter@gmail.com; kadjabio@ gmail.com).

** Doutora em Ciências Ambientais, Professora, UFG, Goiânia, GO (e-mail: gizelda@quimica.ufg.br).

*** Doutora em Ciências Biológicas, Professora Associada I, UFG, Goiânia, GO (e-mail: glaucia@icb.ufg. br).

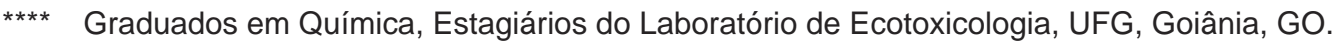

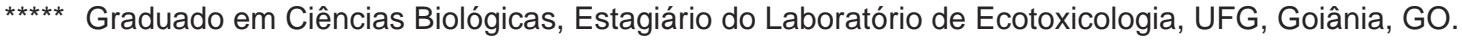

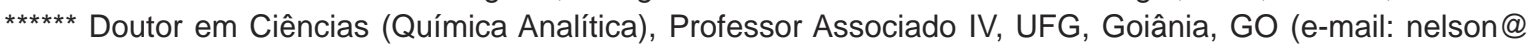
quimica.ufg.br). 


\section{INTRODUÇÃO}

Os peixes representam parte significativa da fauna aquática, apresentado sensibilidade aos poluentes. Esses animais exibem enorme diversidade morfológica em sua biologia e nos habitats que ocupam, constituindo aproximadamente a metade de todas as espécies de vertebrados já descritas (MACHADO, 1999).

A respiração branquial possibilitou aos peixes viver e povoar os ambientes aquáticos. As brânquias dos peixes exercem papeis vitais, pois além de serem o principal sítio de trocas gasosas, também estão envolvidas nos processos de osmorregulação, equilíbrio acidobásico, excreção de compostos nitrogenados e gustação (MACHADO e FANTA, 2003).

O epitélio da brânquia, principal superfície de contato com o ambiente, constitui importante alvo dos poluentes presentes na água devido à sua extensa área superficial (WONG e WONG, 2000). O fato desse órgão estar exposto diariamente às impurezas da água provoca uma série de problemas que em muitos casos pode causar a morte dos peixes devido à sensibilidade do epitélio branquial a substâncias tóxicas. A alta carga de poluentes presente na água pode causar lesões irreversíveis às brânquias, levando o animal à morte.

O epitélio branquial reveste todo o arco branquial, os rastros, os filamentos branquiais e as regiões interlamelares. Trata-se de epitélio pavimentoso composto por vários tipos celulares, incluindo células pavimentosas, células secretoras de muco e células de cloreto, além de células gustativas e de suporte não diferenciadas. O segundo tipo de epitélio, chamado epitélio respiratório, recobre as lamelas respiratórias. Geralmente, é constituído por única camada de células pavimentosas, através das quais ocorrem as trocas gasosas entre o sangue e o meio (EVANS et al., 1982).

Devido ao arranjo celular complexo das brânquias dos peixes, a contaminação da água pode provocar uma série de alterações chamadas de histopatologias. Segundo Machado (1999), as histopatologias mais encontradas em publicações científicas, pela ordem, são: descolamento do epitélio; necrose; fusão lamelar; hipertrofia das células epiteliais; hiperplasia ou fusão das lamelas por crescimento celular, reduzindo a área de superfície respiratória; ruptura das células epiteliais; hipersecreção de muco; aneurisma lamelar; congestão vascular; proliferação de células secretoras de muco e de células de cloreto; infiltração de leucócitos no epitélio; e alterações no espaço sanguíneo delimitado pelas células pilares. A observação dessas alterações permite determinar o grau de toxicidade dos combustíveis fósseis aos peixes e seu impacto em bioma saudável.

Este trabalho foi realizado com o objetivo de analisar o índice de alterações histopatológicas em brânquias de Danio rerio (Cpyrinidae), causado por diferentes níveis de concentração de combustíveis fósseis na água.

\section{MATERIAL E MÉTODOS}

\subsection{ORGANISMO TESTE}

De acordo com o Instituto Ambiental do Paraná seleciona-se organismo teste por critérios como, conhecimento da distribuição da espécie, biologia, hábitos nutricionais e fisiologia, além da estabilidade genética e uniformidade das populações (IAP, 1999). O Danio rerio, originário da Ásia, pertence à família Cyprinidae e atende a esses critérios. Trata-se de peixe de água doce, que vive em cardume em águas com temperaturas entre 18 e $24^{\circ} \mathrm{C}$ e pH de 6,0 a 8,0 . O seu baixo custo, facilidade de obtenção, manutenção e reprodução em condições apropriadas em laboratório fazem com que o $D$. rerio seja muito usado e que já se tenha vasta literatura de sua biologia (CAMPAGNA, 2005). A espécie é considerada sensível e recomendada para testes de sensibilidade e ecotoxicidade pela 
Associação Brasileira de Normas Técnicas (ABNT, 2004), Companhia de Tecnologia de Saneamento Ambiental (CETESB, 1999) e pelo Instituto Brasileiro do Meio Ambiente (IBAMA, 1990).

Os peixes, adquiridos em empresa comercial, estavam na fase adulta, apresentando tamanho médio de $3,14 \mathrm{~cm} \pm 0,51 \mathrm{~cm}$ e peso médio de $0,30 \pm 0,01 \mathrm{~g}$. Os peixes passaram por período de adaptação de 1 mês em aquários de 80 litros, com água de manutenção de boa qualidade (obtida do sistema de tratamento de água) e temperatura em torno dos $25^{\circ} \mathrm{C} \pm 2{ }^{\circ} \mathrm{C}$, sendo alimentados diariamente com dieta apropriada.

A aclimatação inicia-se pela troca paulatina da água de manutenção pela água de diluição (para a manutenção dos peixes e realização dos ensaios, preparada com sais como nutrientes), de modo que os peixes permaneçam somente em água de diluição (100 \%) 48 horas antes do início do teste.

A água de diluição apresentou dureza total de $41,0 \mathrm{mg} / \mathrm{L}$ em $\mathrm{CaCO}_{3} ; \mathrm{pH}$ entre $7.5 \pm 0.2$; condutividade em torno de $130 \mu \mathrm{S} / \mathrm{cm}$ e oxigênio dissolvido $5,4 \mathrm{mg} / \mathrm{L}$. Todos esses valores estão de acordo com as faixas estipuladas pela norma técnica L5.019 da CETESB (1990). A mortalidade de peixes antes do teste de toxicidade permitida pela literatura é de até $5 \%$ do lote.

\subsection{TESTE DE TOXICIDADE AGUDA COM ELUATOS DOS COMBUSTÍVEIS}

O teste de toxicidade aguda consistiu em medir o efeito letal sobre os peixes $D$. rerio adultos, expostos pelo período de 48 horas a várias concentrações dos eluatos de gasolina e diesel. Todos os testes foram realizados com base na norma técnica L 05. 019- I da CETESB (1990).

Os peixes, aclimatados em temperatura média de $25{ }^{\circ} \mathrm{C} \pm 2{ }^{\circ} \mathrm{C}$, foram mantidos em laboratório sob iluminação normal, com foto período diário de $12 \mathrm{~h}$ claro: $12 \mathrm{~h}$ escuro. Retirou-se a alimentação dos peixes durante o teste. $\mathrm{O}$ experimento foi conduzido em aquários de $3 \mathrm{~L}$, com cinco peixes que foram testados em cinco concentrações nos eluatos de gasolina e diesel (100\%, $50 \%, 25 \%, 12,5 \%$ e $6,25 \%$ v/v) e ainda seis concentrações dos eluatos dos destilados de diesel e gasolina $(65,70,75,80,85$ e 97\% v/v). As mesmas séries também foram usadas para testes com bicombustível craqueado de soja.

Registrou-se o número de organismos mortos de hora em hora, durante o período de $8 \mathrm{~h}$ e em seguida durante os períodos de 12 h, 24 h e 48 h. Conforme os organismos morriam eram removidos e acondicionados em recipiente contendo formol a $10 \%$. Os valores da concentração letal $50 \%\left(\mathrm{CL}_{50}\right)$ e seus limites de confiança de $95 \%$ foram determinados usando-se o programa estatístico Trimmed Spearman-Karber (TSK), Versão 1.5 (JIN et al., 1999).

Em todos os experimentos foram monitoradas as variáveis $\mathrm{pH}$, condutividade, temperatura, oxigênio dissolvido e dureza da água no início do teste, 24 h e 48 h após iniciado o ensaio (ABNT, 2003).

\subsection{ANÁLISE HISTOPATOLÓGICA DAS BRÂNQUIAS}

Os animais permaneceram acondicionados em recipiente contendo formol a $10 \%$ até o final dos testes. Após os testes, os animais foram submetidos ao processo de dissecação, no qual foram extraídos os arcos branquiais e fixados em formalina tamponada. As peças extraídas foram submetidas a uma bateria sequencial de álcool para desidratação, e diafanisadas em solução de $50 \%$ xilol e álcool. Os arcos branquiais foram emblocados com parafina e cortados em micrótomo, sendo os cortes fixados em laminas, e corados com Hematoxilina e Eosina. Após serem coradas, as laminas foram montadas e observadas ao microscópio óptico (LABIOCEL, 2002). 


\section{RESULTADOS E DISCUSSÃO}

Em ambos os testes foi possível observar alterações diversas, como necrose, hiperplasia e aneurisma nas células do epitélio, ocorrendo em alguns casos alterações mais severas em concentrações menores. Thophon et al. (2003) assinalaram a presença de edema acompanhado pelo destacamento do epitélio lamelar como sendo o primeiro sinal de patologia em peixes. $\mathrm{O}$ espessamento do epitélio filamentar e lamelar foi observado em peixes expostos a diferentes poluentes (ARELLANO et al., 2000). O aumento do epitélio pode ser devido à proliferação de células de cloro e de células indiferenciadas (DANG et al., 1999). A exposição de organismos a baixas concentrações de determinado produto por longo período de tempo pode resultar no mesmo efeito da exposição a altas concentrações por curto período de tempo (FERREIRA, 2003). Isso geralmente ocorre porque em concentrações mais elevadas os peixes apresentam morte precoce, não havendo tempo de reação defensiva do organismo. Em animais expostos a altas concentrações é comum se observar a presença de necroses e a ruptura do epitélio branquial. Tais lesões refletem o efeito direto dos poluentes (TEMMINK et al., 1983), o que geralmente ocorre em condições de maior toxicidade (ABEL, 1976).

Algumas histopatologias estão relacionadas ao mecanismo de defesa da brânquia como, hipersecreção de muco, hipertrofia de células e infiltração leucocitária, mas esse processo em grande intensidade prejudica o animal causando asfixia e perda das funções branquiais. A proliferação do epitélio filamentar e a fusão de lamelas são alterações histológicas que também funcionam como mecanismos de defesa, porque diminuem a área de superfície vulnerável da brânquia e/ou aumentam a barreira de difusão ao poluente (KARLSSON-NORRGREN et al., 1985; ERKMEN e KOLANKAYA, 2000). Essas respostas dificultam o acesso do poluente ao sangue, mas prejudicam a realização de trocas gasosas (McDONALD e WOOD, 1993).

As toxinas podem penetrar nas brânquias e competir com os sais absorvidos para o controle de osmorregulação, obstruindo as vias de acesso da célula e evitando tanto as trocas gasosas como a osmorregulação. Substâncias como metais pesados e ácidos graxos podem atravessar o epitélio respiratório, chegar diretamente à corrente sanguínea e afetar o fígado.

Os animais que não foram expostos aos combustíveis apresentaram brânquias saudáveis sem nenhuma alteração histológica, ou até mesmo morfofisiológica dos arcos branquiais como pode ser observado na Figura 1.

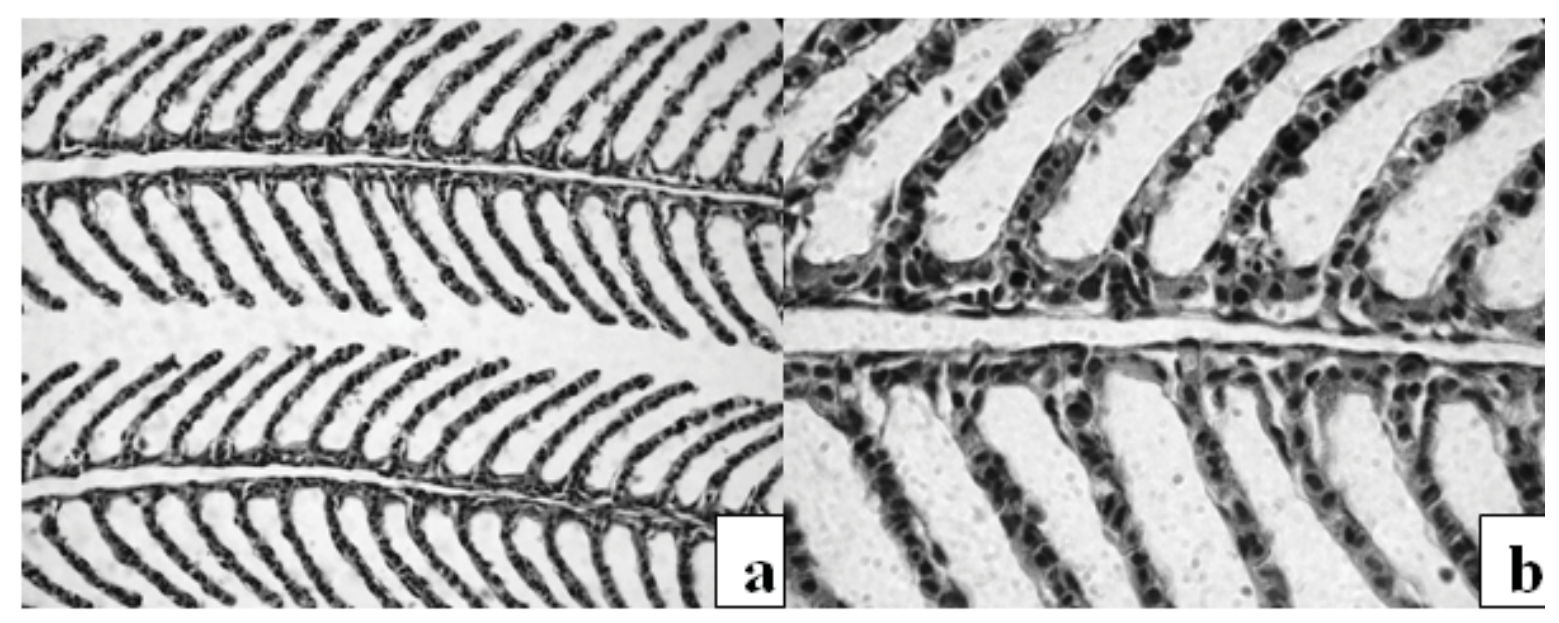

\section{FIGURA 1- FOTOMICROGRAFIA DA BRÂNQUIA DE D. rerio SEM EXPOSIÇÃO A COMBUSTIVEIS FOSSEIS}

a) Corado em hematoxilina-eosina (HE) aumento de $400 \mathrm{X}$. b) Corado em HE aumento de $1000 \mathrm{X}$. 
Os animais expostos à gasolina pura (concentração $100 \%$ ) apresentaram as seguintes alterações: hipertrofia das células de muco $(\mathrm{HM})$ e de cloreto $(\mathrm{HC})$ e necrose do epitélio respiratório (N) (Figura 2a). Os animais expostos à gasolina comum $100 \%$ (Figura 2b) apresentaram necrose do epitélio respiratório $(\mathrm{N})$ e hipertrofia das células de cloreto $(\mathrm{HC})$ e de muco $(\mathrm{HN})$.

Nos animais expostos à gasolina comum (concentração intermediaria 80 \%) (Figura 2c) verificou-se severa degradação do tecido com as seguintes histopatologias: hipersecreção de muco $(\mathrm{HM})$, e total descolamento do epitélio respiratório $(\mathrm{N})$.

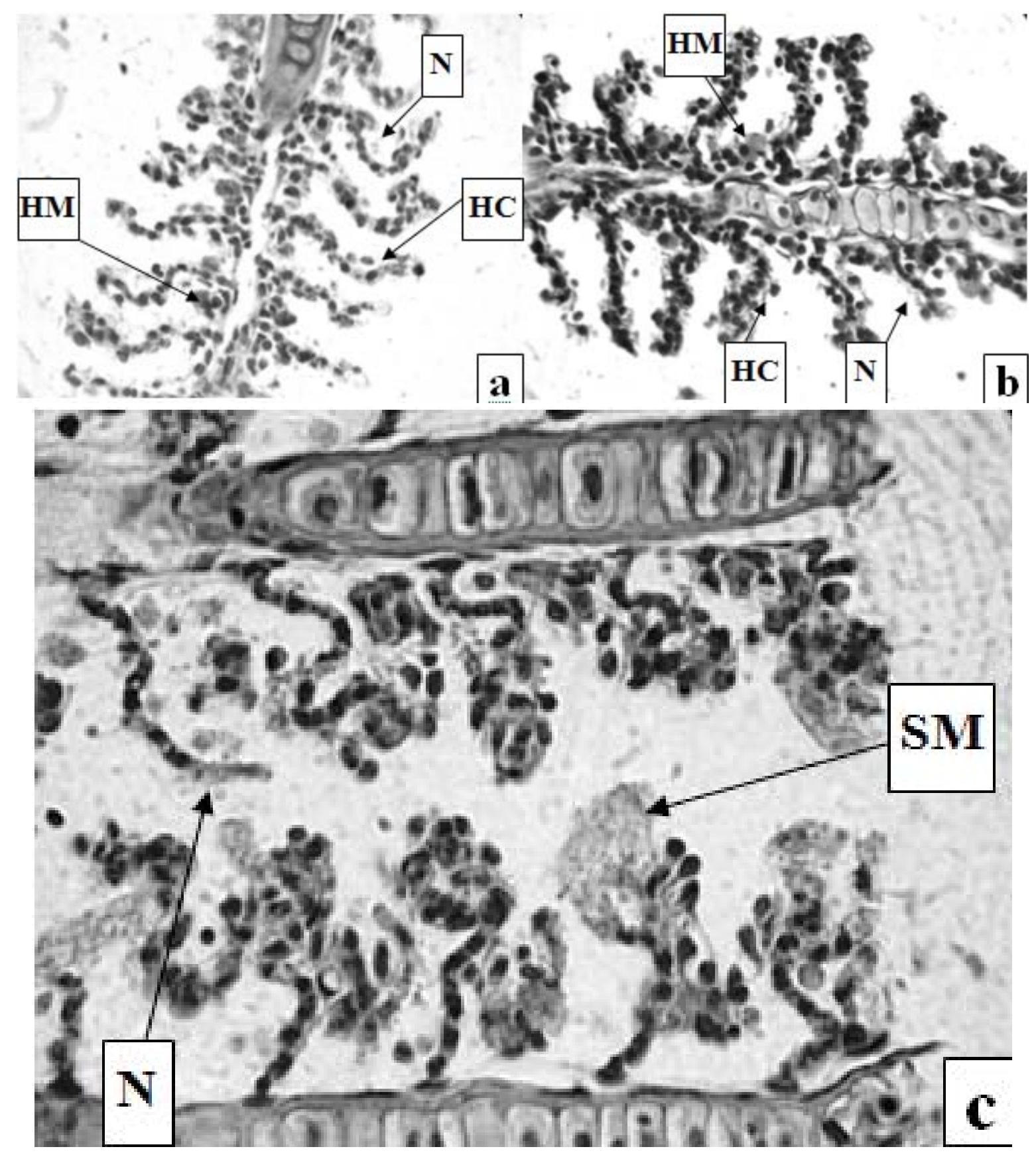

\section{FIGURA 2 - FOTOMICROGRAFIA DA BRÂNQUIA DE D. rerio EXPOSTOS A GASOLINA}

Nota: a) Animais expostos à concentração $100 \%$ de gasolina pura = hipertrofia das células de muco (HM), hipertrofia das células de cloreto $(\mathrm{HC})$ e necrose das células do epitélio respiratório $(\mathrm{N})$. b) Animais expostos à concentração $100 \%$ de gasolina comum $=$ necrose do epitélio respiratório $(\mathrm{N})$, hipertrofia das células de cloreto $(\mathrm{HC})$ e hipertrofia das células de muco (HM). c) Animais expostos à concentração de $80 \%$ gasolina comum (concentração intermediaria) = hipersecreção de muco (SM) e total descolamento do epitélio respiratório seguido por necrose $(\mathrm{N})$. 
Os peixes que foram expostos ao óleo diesel na concentração de $100 \%$ (Figura 3a) apresentaram leve descolamento do epitélio respiratório (D) e aneurisma (AN) consequente do rompimento de seio venoso. Nos testes com as concentrações intermediárias (80\%), os resultados foram extremamente diferentes dos observados anteriormente, verificando-se necrose das células do epitélio respiratório $(\mathrm{N})$ e total descolamento do epitélio respiratório, além de lesões nas células da cartilagem de forma bastante clara (Figura 3b).

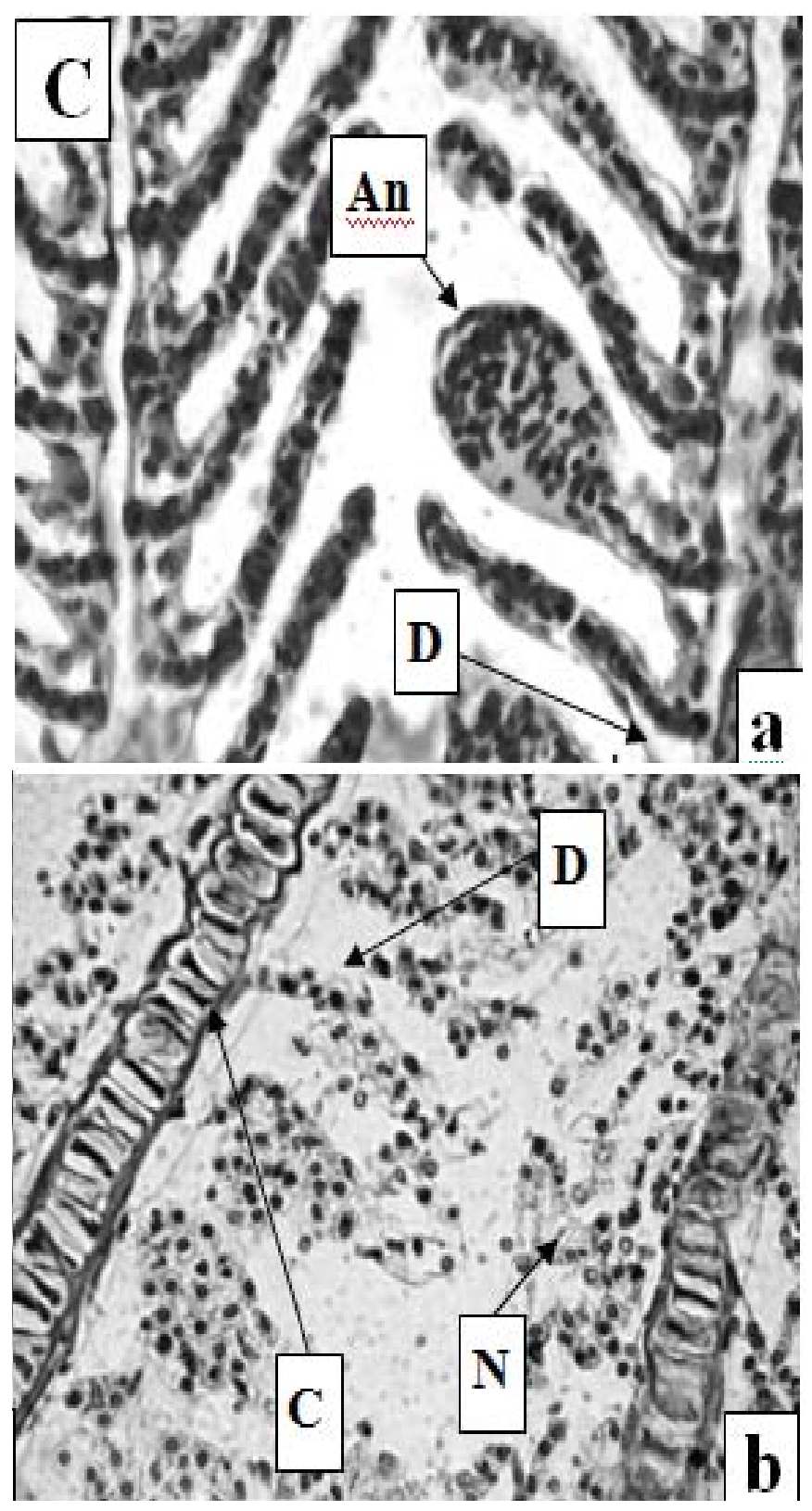

\section{FIGURA 3 - FOTOMICROGRAFIA DA BRÂNQUIA DE D. rerio EXPOSTO À ÓLEO DIESEL}

\section{CONCLUSÃO}

Conclui-se que os combustíveis fósseis apresentaram alto nível de toxicidade aos peixes devido à sua composição química. Os diferentes níveis de concentração resultaram em danos variados e níveis mais elevados podem levar a morte do animal durante curto período de exposição. A exposição aos combustíveis fósseis causa uma série de alterações histológicas, sendo as mais graves observadas em animais com maior tempo de exposição. 


\section{ABSTRACT \\ EVALUATION OF THE GILLS OF Danio rerio EXPOSED TO DIFFERENT CONCENTRATIONS OF GASOLINE AND DIESEL}

The presented work aimed to study the effect of fossil fuels in the gills of Danio rerio (Cyprinidae) fish. The animals were exposed to different gasoline concentrations and diesel oil (from $6.25 \%$ to $100 \%$ ) on ecotoxicological tests. The results demonstrated that the fuels in its common or pure composition are lethal, and in some cases cause severe injuries such as necrosis, hypertrophy of the cells, aneurisms and edemas, causing the death of these animals.

KEY-WORDS: HISTOPATHOLOGY; GILL; ECOTOXICOLOGY; Danio rerio.

\section{REFERÊNCIAS}

1 ABEL, P.D. Toxic action of several lethal concentrations of an anionic detergent on the gills of the brown trout (Salmo trutta L.). J. Fish Biol., v.9, p.441-446, 1976.

2 Associação Brasileira de Normas Técnicas (ABNT). NBR 10.006: solubilização de resíduos - procedimentos. Rio de Janeiro, 2004. p.3.

3 Associação Brasileira de Normas Técnicas (ABNT). NBR 13.373: ecotoxicologia aquática - ensaio de toxicidade crônica com Ceriodaphnia sp. (Crustacea, Cladocera). Rio de Janeiro, 2003. p.4-6.

4 ARELLANO, J.M.; BLASCO, J.; ORTIZ, J.B. et al. Accumulation and histopathological effects of copper in gills and liver of Senegales Sole, Solea senegalensis and toad fish, Halobatrachus didactylus. Ecotoxicol. Environ. Restor, v.3, p.22-28, 2000.

5 CAMPAGNA, Aline Fernanda. Toxicidade dos sedimentos da Bacia Hidrográfica do Rio Monjolinho (São Carlos SP): ênfase nas substâncias cobre, aldrin e heptacloro. 2005. 268 f. Dissertação (Mestrado em Qualidade e Produtividade Animal), Faculdade de Zootecnia e Engenharia de Alimentos, Universidade de São Paulo, Pirassununga, 2005.

6 Companhia de Tecnologia de Saneamento Ambiental (CETESB). Água: teste de toxicidade aguda com peixe. São Paulo, 1990. (Parte 1 - Normalização Técnica L 5.019-I).

7 DANG, Z.; LOCK, R.; FLIK, G. et al. Metallothionein response in gills of Oreochromis mossambicus exposed to copper in fresh water. Am. J. Physiol., v.277, p.320-331, 1999.

8 ERKMEN, B.; KOLANKAYA, D. Effects of water quality on epithelial morphology in the gill of Capoeta tinca living in two tributaries of Kizilirmak River, Turkey. Bull. Environ.Contam. Toxicol., v.64, p.418-425, 2000.

9 FERREIRA, C.M. Testes de toxicidade aquática para monitoramento ambiental. Biológico, São Paulo, v. 65, n. 1/2, p.1718, dez.2003.

10 GARCIA-SANTOS, S.; MONTEIRO, S.M.; CARROLA, J.; FONTAINHAS-FERNANDES, A. Alterações histológicas em brânquias de tilápia nilótica, Oreochromis niloticus, causadas pelo cádmio. Arq. Bras. Med. Vet. Zootec., v.59, n.2, p.376-381, 2007.

11 Instituto Ambiental do Paraná (IAP). Manual de avaliação de impactos ambientais. Importância dos parâmetros ecotoxicológicos em estudos ambientais. 3. ed. Curitiba: SEMA/IAP/GTZ, 1999.

12 Instituto Brasileiro do Meio Ambiente (IBAMA). Manual de testes para a avaliação da toxicidade de agentes químicos. Brasília, 1990.

$13 \mathrm{JIN}, \mathrm{H}$.; YANG, X.; YIN, D.; YU, H. A case study on identifying the toxicant in effluent discharged from a chemical plant. Marine Pollution Bulletin, v.39, p.122-125, jan.1999.

14 KARLSSON-NORRGREN, L.; RUNN, P.; HAUX, C. et al. Cadmium-induced changes in gill morphology of zebrafish, Brachydanio rerio (Hamilton-Uchanan) and rainbow trout Salmo gairdneri Richardson. J. Fish Biol., v.27, p.81-95, 1985.

15 Laboratório de Biologia Celular (LABIOCEL). Manual de técnicas em histologia e biologia celular do Laboratório de Biologia Celular da Faculdade de Medicina da Universidade de São Paulo. São Paulo: Faculdade de Medicina da USP, 2002.

16 MACHADO, M.R. Uso de brânquias de peixes como indicadores de qualidade das águas. UNOPAR Cient., Ciênc. Biol. Saúde, Londrina, v.1, n.1, p.63-76, out.1999. 
epithelium of a freshwater fish Metynnis roosevelti. Braz. Arch. Biol. Technol., v.46, p.361-372, 2003.

18 MCDONALD, D.G.; WOOD, C.M. Branchial mechanisms of acclimation to metals in freshwater fish. In: FISH ecophysiology. London: Chapman \& Hall, 1993. p.297-321.

19 TEMMINK, J.; BOUWMEISTER, P.; DE JONG, P. et al. An ultrastructural study of chromateinduced hyperplasia in the gills of rainbow trout (Salmo gairdneri). Aquatic Toxicol., v.4, p.165-179, 1983

20 THOPHON, S.; KRUATRACHUE, M.; UPATHAM, E.S. et al. Histopathological alterations of white seabass, Lates calcarifer, in acute and subchronic cadmium exposure. Environ. Pollut., v.121, p.307-320, 2003.

21 WONG, C.K.; WONG, M.H. Morphological and biochemical changes in the gills of Tilapia (Oreochromis mossambicus) to ambient cadmium exposure. Aquatic Toxicol., v.48, p.517-527, 2000. 